\title{
Relating Whole-plant Photosynthesis to Physiological Acclimations at Leaf and Cellular Scales under Drought Stress in Bedding Plants
}

\author{
Krishna Nemali ${ }^{1}$ \\ Department of Horticulture and Landscape Architecture, Purdue University, West Lafayette, IN \\ 47907
}

\author{
Marc W. van Iersel \\ Department of Horticulture, University of Georgia, Athens, GA 30602
}

AdDitional INDEX wORDs. capacitance probes, chlorophyll fluorescence, datalogger, drought resistance

\begin{abstract}
Bedding plants are at increased risk for exposure to drought stress during production because they are grown in small containers. Physiological mechanisms of bedding plants at leaf and cellular scales that regulate wholeplant photosynthesis under drought conditions are not well understood. This information can be useful for screening bedding plant cultivars with improved drought-tolerance and generate guidelines to mitigate drought stress during production. We subjected drought-sensitive salvia (Salvia splendens 'Bonfire Red') and drought-tolerant vinca (Catharanthus roseus 'Cooler Peppermint') to gradual drought stress inside whole-plant gas exchange chambers. Substrate water content $(\Theta)$, whole-plant net photosynthesis $\left(P_{n_{n} \_a v g}\right)$, whole-plant respiration $\left(R_{d \_a v g}\right)$, and daily carbon gain (DCG) were measured continuously, whereas stomatal conductance $\left(g_{S}\right)$ to water, leaf water $\left(\Psi_{L}\right)$, osmotic $\left(\Psi_{S}\right)$, and turgor $\left(\Psi_{P}\right)$ potentials were measured at the start and end of the drought phase. In addition, $\Psi_{S}$ was measured before exposure to stress and after thoroughly rehydrating plants. Dark-adapted quantum efficiency (dark-adapted $\Phi_{P S I I}$ ) was measured after rehydrating plants. The results indicated that, at whole-plant scale, vinca continued to uptake water at lower $\Theta$ levels than the $\Theta$ level that resulted in wilting of salvia. There were no differences in $R_{d \_ \text {_avg }}$; however, $P_{n_{-} \text {avg }}$ and DCG of salvia decreased at a higher $\Theta$ level than that of vinca. This indicated that salvia experienced drought stress at a higher $\Theta$ level than did vinca. At the leaf scale, there were no differences in $\Psi_{L}$; however, a more negative $\Psi_{S}(P=0.06)$ and significantly higher $\Psi_{P}$ were observed in vinca (compared to salvia) under drought conditions. In addition, $\Psi_{S}$ was not different between species before exposure to drought, whereas $\Psi_{S}$ of rehydrated leaves after exposure to drought in vinca was significantly lower than that in salvia. Moreover, $\Psi_{S}$ of rehydrated leaves after exposure to drought was significantly lower than that observed before exposure to drought in vinca. This indicated osmotic adjustment (OA) in vinca under drought conditions. Dark-adapted $\Phi_{P S I}$ was lower in salvia than in vinca after exposure to drought, indicating damage to photosynthetic mechanisms. Our results suggested that increased OA likely helped to maintain higher $\Psi_{P}$ under drought conditions and continuation of water uptake at lower $\Theta$ in vinca compared to salvia. In addition, healthier photosynthetic mechanisms of vinca (compared to salvia) under drought conditions likely resulted in its higher $P_{n_{-} a v g}$ and DCG at lower $\Theta$. Screening for $O A$ and dark-adapted $\Phi_{P S I I}$ may be useful for developing drought-tolerant bedding plant cultivars.
\end{abstract}

There has been an increased occurrence of moderate to severe levels of drought in the United States during the past decade (National Aeronautics and Space Administration, 2014; National Oceanic and Atmospheric Administration, 2016). For field crops, considerable efforts have been made to understand the physiological responses of crop species to drought (Castiglioni et al., 2008; Ennahli and Earl, 2005; Nemali et al., 2015). However, there is limited research related to physiological mechanisms that help bedding plants cope with drought stress. Bedding plants comprise an important sector of the U.S. greenhouse industry with sales estimated at $\approx \$ 1.86$ billion in 2015 (U.S. Department of Agriculture, 2015). Drought conditions can be more aggravated in bedding plants than field-grown plants because they are grown in small-volume containers in greenhouses. When exposed to drought, field crops can extract water from deeper soil layers and resist drought by preferentially increasing root growth. However, small container

Received for publication 13 Feb. 2019. Accepted for publication 15 Apr. 2019. ${ }^{1}$ Corresponding author. E-mail: knemali@purdue.edu. volumes can restrict root growth during bedding plant production, thus making them prone to increased stress levels under drought conditions. Moreover, hydraulic conductivity of soilless substrates used in bedding plant production declines rapidly with small changes in substrate water content (da Silva et al., 1993), making it more difficult for plants to extract water when $\Theta$ is low in the substrate.

Photosynthesis is central to crop growth and highly sensitive to drought stress (Tezara et al., 1999). Understanding photosynthesis responses to drought stress can be more critical for bedding plants because they are at increased risk for exposure to drought due to production in small-volume containers. Although several studies have examined photosynthesis responses of bedding plants under drought conditions (Kim and van Iersel, 2011; Nemali and van Iersel, 2008; Niu and Rodriguez, 2006), there is limited research-based information that connects physiological acclimation to drought in leaves and cells to whole-plant photosynthesis in bedding plants. This information can be useful for 1) developing fundamental knowledge regarding plant physiological responses to drought, 2) generating 
guidelines to mitigate drought stress during production, 3) selecting species for production, and 4) developing new cultivars that are resilient under drought stress through plant breeding.

Plants can acclimate on multiple scales in response to drought stress (Chapman and Augé, 1994). On the whole-plant scale, some species partition relatively more biomass to roots to increase water uptake (Jaramillo et al., 2013; Lynch, 2007a, 2007 b) as a way to maintain plant water status and photosynthesis under drought conditions. This acclimation response may not be an advantage in greenhouse-grown bedding plants because both root growth and available water are restricted in small containers. Morphological changes in shoots also occur in response to exposure to drought. This may involve producing smaller leaves to lower water loss through transpiration from plants (Nemali et al., 2015; Tardieu et al., 2014) and abscission of older leaves. A lower leaf area can reduce photosynthesis on the whole-plant scale and overall carbon gain in plants. However, if this lower leaf area can help to maintain favorable plant water status, then the decline in whole-plant photosynthesis may be less pronounced under drought conditions.

A reduction in water loss under drought conditions on the leaf scale is achieved by transiently lowering $g_{\mathrm{S}}$ (Chaves et al., 2003), which, in turn, can help to maintain the leaf photosynthesis rate, albeit at a lower rate for a longer period under drought conditions. There is good correlation between $g_{\mathrm{S}}$ and leaf water potential in plants exposed to drought stress (Boyle et al., 2016; Comstock and Mencuccini, 1998). Lower $\Psi_{\mathrm{L}}$ can increase stomatal sensitivity to abscisic acid (Tardieu and Davies 1992). Abscisic acid-mediated reduction in $g_{\mathrm{S}}$ during drought conditions is well known (Boyle et al., 2016; Comstock and Mencuccini, 1998; Tardieu and Davies 1992). The $g_{\mathrm{S}}$ in many bedding plant species declines when substrate water content decreases to less than 15\% (v/v) (Nemali and van Iersel, 2008).

On the cellular scale, osmotic adjustment is an acclimation response to drought that concentrates compatible solutes inside cells (Sanders and Arndt, 2012; Serraj and Sinclair, 2002). This lowers $\Psi_{\mathrm{L}}$ and maintains the $\Psi$ gradient needed for water movement into roots from the substrate and helps to maintain positive turgor potential under drought conditions (Nemali and Stephens, 2014). Positive $\Psi_{\mathrm{P}}$ in the cells can enable continuation of metabolism during drought. However, a significant fraction of carbon gained by maintaining metabolism under drought conditions is used in the synthesis compatible solutes needed for OA, which can reduce overall plant growth (McCree, 1986). Light harvesting mechanisms, including photosystems, are generally tolerant to drought stress; however, severe stress levels can damage photosystem II, and photosynthesis may not completely recover after recovery from severe drought stress (Flexas et al., 1999).

The objective of this study was to understand how droughtsensitive and drought-tolerant bedding plant species respond to drought stress by relating differences in whole-plant photosynthesis to physiological responses observed on leaf and cellular scales for both species when exposed to a gradual drought stress.

\section{Materials and Methods}

Plant materials and environmental conditions. Seeds of salvia ('Bonfire Red') and vinca ('Cooler Peppermint') were sown in standard flats $(0.55 \times 0.20 \times 0.06 \mathrm{~m})$ filled with a soilless substrate (Fafard 2P; Fafard, Anderson, SC) and germinated under a mist system. These species were selected based on our previous research (Nemali and van Iersel, 2008) that indicated that vinca is drought-resistant and salvia is drought-sensitive when grown in containers. The seeds were sown at different times because replications were spaced over time. At each time, one flat was sown for each species and two more flats were filled with the same soilless substrate and left unsown. Approximately 1 week after germination, seedlings were thinned to 32 per flat ( 8 rows $\times 4$ seedlings per row). Plants were subirrigated with a $15 \mathrm{~N}-2.2 \mathrm{P}-12.5 \mathrm{~K}$ water-soluble fertilizer (Peters 15-5-15 Cal-Mag, Peat-lite special; Scotts, Marysville, $\mathrm{OH})$ at a rate of 1.0 to $1.5 \mathrm{dS} \cdot \mathrm{m}^{-1}\left(150-225 \mathrm{mg} \cdot \mathrm{L}^{-1} \mathrm{~N}\right)$ in an ebb-and-flow system until no gaps were visually detected and the leaf canopy completely covered the substrate. Canopy coverage occurred earlier (2-3 d) for salvia than for vinca. The mean and SD of temperature, relative humidity (RH), and daily light integral (DLI) inside the greenhouse were $21.5 \pm 0.9^{\circ} \mathrm{C}$, $44.7 \% \pm 11.3 \%$, and $7.4 \pm 2.24 \mathrm{~mol} \cdot \mathrm{m}^{-2} \cdot \mathrm{d}^{-1}$, respectively.

Plants inside gas exchange Chambers. After canopy coverage was reached, the trays containing plants were shifted to a multi-chamber, semi-continuous, open-flow whole-plant gas exchange system (van Iersel and Bugbee, 2000) arranged inside a growth chamber. Briefly, the gas exchange system measured the net $\mathrm{CO}_{2}$ exchange rate of a group of 32 plants once every $10 \mathrm{~min}$ for a period of $30 \mathrm{~s}$ during light [whole-plant net photosynthesis (micromoles per second)] and dark [wholeplant respiration (micromoles per second)]. Approximately $0.4 \mathrm{~L} \cdot \mathrm{s}^{-1}$ of air from outside the building was blown into each chamber using a rotary vane blower (DT 3.4; Becker, Cuyahoga Falls, OH). The flow rate was measured using a flow meter (GFM37-32; Aalborg Instruments and Controls, Monsey, $\mathrm{NY})$. In addition, differences in the $\mathrm{CO}_{2}$ concentration $\left[\Delta \mathrm{CO}_{2}\right.$ (micromoles per mole)] of incoming and outgoing air from each chamber during the 30-s measurement times were measured with an IR gas analyzer (LI-6262; LI-COR Biosciences, Lincoln, NE). Later, the net $\mathrm{CO}_{2}$ exchange rate was calculated as the product of the flow rate and $\Delta \mathrm{CO}_{2}$. The unsown trays were also shifted into gas exchange chambers to correct gas exchange rates for microbial breakdown of the substrate. The values of $P_{n}$ and $R_{d}$ were corrected for microbial respiration from the substrate by subtracting the $\mathrm{CO}_{2}$ exchange rate from unsown trays.

Before shifting trays to the gas exchange chambers, the substrate in all trays was thoroughly wetted. Inside the gas exchange chambers, the substrate was allowed to dry until plants started to show signs of wilting. The time between placing trays inside the gas exchange chambers and wilting of plants constituted a drought cycle. The drought cycle depended on species and ranged from 7 to $14 \mathrm{~d}$. After a drought cycle, the trays were taken out of the gas exchange chambers, the substrate was again rehydrated, and trays were placed back inside the gas exchange chambers. There were two drought cycles for all trays. The measurements of the second cycle were used in the analysis to ensure that plants were acclimated to drought conditions before data collection. In addition, some measurements were performed before placing plants inside the gas exchange system (before drought exposure) and after thoroughly rehydrating plants at the end of the second drought cycle.

ENVIRONMENTAL CONTROL INSIDE GAS EXCHANGE CHAMBERS. The growth chamber was programmed to light and dark cycles of 4 and $2 \mathrm{~h}$, respectively. This enabled us to start any drought 
cycle on the same day after rehydrating wilted plants from the previous cycle. During the gas exchange study, the DLI during $16 \mathrm{~h}$ of light was maintained similar to the DLI received by plants inside the greenhouse by adjusting the photosynthetic photon flux density (PPFD) incident for plants inside the gas exchange chambers. The instantaneous $P P F D$ maintained inside the growth chamber was $\approx 130 \mu \mathrm{mol} \cdot \mathrm{m}^{-2} \cdot \mathrm{s}^{-1}$ and resulted in a DLI of $7.5 \mathrm{~mol} \cdot \mathrm{m}^{-2} \cdot \mathrm{d}^{-1}$. The RH inside the gas exchange chambers was measured using a temperature and humidity sensor (HTO-45R; Rotronic Instruments, Crawley, UK). In general, $\mathrm{RH}$ inside gas exchange chambers depended on the $\Theta$ and varied between $75 \%$ to $30 \%$ as the $\Theta$ decreased during a drought cycle. The temperature inside the gas exchange chambers was regulated by heater strips controlled by a datalogger (CR10T; Campbell Scientific, Logan, UT) based on the temperature readings and maintained at $21^{\circ} \mathrm{C}$.

Measurements. Substrate water content was measured once every 10 min using dielectric soil moisture sensors (ECH2O-10; Meter Group, Pullman, WA) connected to a datalogger (CR10; Campbell Scientific). The datalogger measured substrate water content based on a substrate-specific calibration equation involving the voltage output of the probes $[\ln (\Theta)=-6.99+$ $\left.1.58 \cdot 10^{-2} \mathrm{mV}-9.91 \cdot 10^{-6} \cdot \mathrm{mV}^{2} ; R^{2}=0.91\right]$, where $\Theta$ is the substrate-specific water content in cubic meters per cubic meter. More details about the calibration of soil moisture sensors are described elsewhere (Nemali et al., 2006). The daily average $\Theta$ was calculated from continuous measurements performed at 10-min intervals. Using this average, the daily decrease in $\Theta$ $\left[\Theta_{\text {change }}\right.$ (cubic meters per cubic meter per day)] was calculated as $\Theta_{n}-\Theta_{n-1}$, where $n$ and $n-1$ are 2 consecutive days.

Continuous measurements of $P_{n}$ and $R_{d}$ during the light and dark periods, respectively, were used to calculate $\mathrm{P}_{\mathrm{n} \_ \text {avg }}$ and $\mathrm{R}_{\mathrm{d} \_a v g}$ for the daily light and dark periods. The daily carbon gain by a group of 32 plants [millimoles per day (a measure of the growth rate of the plants)] was calculated as:

$$
D C G=\frac{\left[\left(P_{\text {navg }} \times 3600 \times 16\right)-\left(R_{\text {davg }} \times 3600 \times 8\right)\right]}{1000},
$$

where 3600 refers to the number of seconds per hour, 16 and 8 are the total hours of light and dark during $1 \mathrm{~d}$, and dividing by 1000 expresses DCG in millimoles. To normalize for canopy size differences among replications and between the two species, $\mathrm{P}_{\mathrm{n} \_a v g}, \mathrm{R}_{\mathrm{d} \_a v g}$, and DCG values were also expressed as the percent change from the observed maximum value for any replication during a drought cycle.

At the start and end of the second drought cycle, $g_{\mathrm{S}}, \Psi_{\mathrm{L}}, \Psi_{\mathrm{S}}$, and $\Psi_{\mathrm{p}}$ of three to four plants in each replication were measured. Before exposing plants to drought conditions, and after thoroughly rehydrating plants following the second drought cycle, $\Psi_{\mathrm{L}}, \Psi_{\mathrm{s}}$, and $\Psi_{\mathrm{p}}$ of turgid leaves were measured to assess OA. Dark-adapted $\Phi_{\text {PSII }}\left(F_{\mathrm{v}} / F_{\mathrm{m}}\right)$ was measured after thoroughly rehydrating plants following the second drought cycle. Leaf water potential was measured using leaf-cutter thermocouple psychrometers $(6.4 \mathrm{~mm}$ diameter $\times 23.3 \mathrm{~mm}$ length; model 76; J.R.D. Merrill, Logan, UT) for three to four leaves per experimental unit after equilibration at $25^{\circ} \mathrm{C}$ for $4 \mathrm{~h}$. The psychrometers were kept in a freezer overnight to kill the leaf samples after $\Psi_{\mathrm{L}}$ measurements to determine $\Psi_{\mathrm{s}}$ from lysed cells. Measurements of $\Psi_{\mathrm{s}}$ were performed again after equilibrating the psychrometers at $25{ }^{\circ} \mathrm{C}$ for $4 \mathrm{~h}$. Leaf $\Psi_{\mathrm{P}}$ was calculated as the difference between $\Psi_{\mathrm{S}}$ and $\Psi_{\mathrm{L}}$. The $g_{\mathrm{S}}$ in three to four plants from each replication was measured using a steady-state leaf porometer (LI-1600; LI-Cor Biosciences). Plants were dark-adapted for 40 to $60 \mathrm{~min}$ before measuring dark-adapted $\Phi_{\text {PSII }}$ using a pulse-amplitude modulated chlorophyll fluorometer with a saturating pulse $\left(>8000 \mu \mathrm{mol} \cdot \mathrm{m}^{-2} \cdot \mathrm{s}^{-1}\right.$; mini-PAM; Walz, Effeltrich, Germany). Data from subsamples within the same experimental unit were averaged before statistical analysis.

EXPERIMENTAL DESIGN AND STATISTICAL ANALYSIS. The experiment used a randomized complete block design with two species and six replications. Replications were spaced over time, and data were analyzed by using both analysis of variance (ANOVA) and regression procedures of statistical analysis software (SAS version 9.4; SAS Institute, Cary NC). Main and interactive effects of species and time on $\mathrm{P}_{\mathrm{n} \_a v g}, \mathrm{R}_{\mathrm{d} \_a v g}, \mathrm{DCG}$, $\Psi_{\mathrm{L}}, \Psi_{\mathrm{s}}, \Psi_{\mathrm{p}}$, and dark-adapted $\Phi_{\mathrm{PSII}}$ were tested using ANOVA and SAS (SAS Institute). Means were separated using the Tukey-Kramer procedure. For all comparisons, $P \leq 0.05$ was considered statistically significant. The following nonlinear regression (Gompertz model) was fitted to describe the response of normalized $\mathrm{P}_{\mathrm{n} \_a v g}, \mathrm{R}_{\mathrm{d} \_a v g}$, and DCG $(f)$ to decreasing substrate $\Theta: f=100 \cdot \exp ^{-\exp }{ }^{\left[-\frac{\left(\theta-\theta_{o}\right)}{b}\right]}$, where $\Theta$ is the substrate moisture content and $\mathrm{b}$ and $\Theta_{0}$ are regression parameters that describe the slope (percent change in the dependent variable per unit change in $\Theta$ ) and displacement (cubic meters per cubic meter) of the curve along the $\mathrm{x}$-axis, respectively. The nonlinear regression was fitted to all replications using the nonlinear procedure of SAS (SAS Institute). The parameter values of $\mathrm{b}$ and $\Theta_{0}$ were estimated for each replication from the fitted regression curves. These parameters were analyzed for the main effect of species using ANOVA and SAS (SAS Institute). Fitted regressions were considered statistically different between species if $\mathrm{b}$ and/or $\Theta_{0}$ were significantly different $(P \leq 0.05)$ between species. The threshold $\Theta$ at which $\mathrm{P}_{\mathrm{n} \_ \text {avg }}, \mathrm{R}_{\mathrm{d} \_a v g}$, and DCG decreased by $10 \%$ from the maximum was estimated from the fitted equations.

\section{Results and Discussion}

\section{Whole-plant responses to drought stress}

SubSTRATE WATER CONTENT. The substrate water content of both species decreased exponentially during the drought cycle (Fig. 1A). Although $\Theta$ was numerically higher for salvia compared to vinca during the initial drought period, the average $\Theta$ was not statistically different between the two species (Fig. 1A). After $8 \mathrm{~d}$ of drought treatment, salvia plants started to show wilting. For vinca, wilting symptoms were observed after an additional $6 \mathrm{~d}$ (i.e., $14 \mathrm{~d}$ after drought treatment). Vinca plants wilted at a significantly lower $\Theta$ than did salvia ( 0.05 vs. $\left.0.09 \mathrm{~m}^{3} \cdot \mathrm{m}^{-3} ; P=0.001\right)$.

The daily decrease in substrate water content during the drought depended on species (Fig. 1B). A higher $\Theta_{\text {change was }}$ observed in salvia than in vinca during the initial days of drought stress. As the canopy completely covered the substrate of both species during the drought phase, $\Theta_{\text {change }}$ was mostly affected by differences in plant water uptake rather than evaporation. This indicated that the water uptake of salvia was higher than that of vinca initially, when $\Theta$ was high. The larger canopy size of salvia compared to that of vinca (1.11 vs. $0.62 \mathrm{~m}^{2}$ ) likely increased transpiration and water uptake of salvia at high $\Theta$. Because of the initially high water uptake, $\Theta$ of salvia quickly decreased to a level similar to that of vinca within 

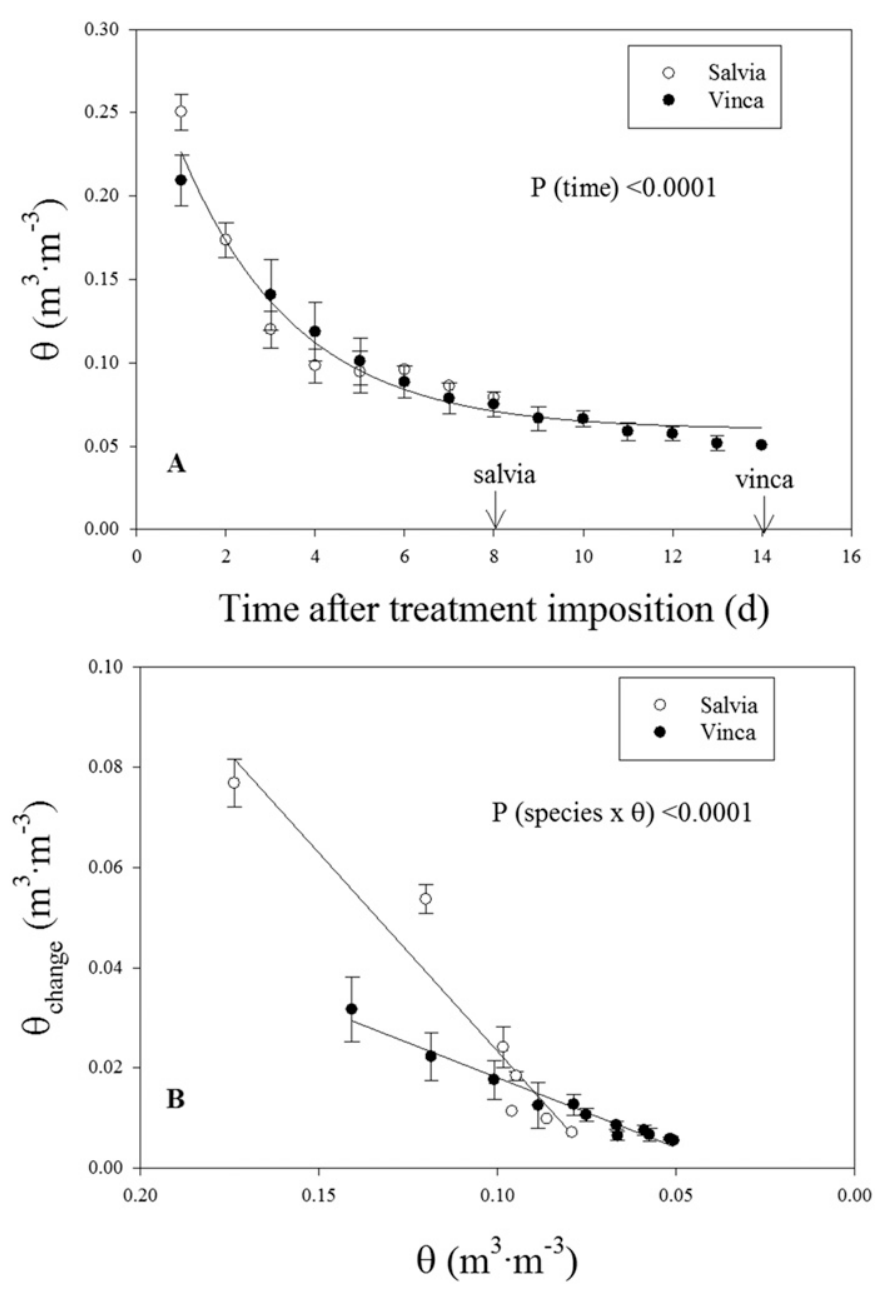

Fig. 1. (A) Substrate volumetric water content $(\Theta)$ measured using dielectric moisture sensors on different days after withholding water during the second drought cycle for salvia and vinca. Error bars represent SEM $(n=5-6)$. The substrate water content was not different between species, but the average $\Theta$ significantly differed with time. An exponential equation, $\Theta=0.06+$ $0.245 \mathrm{e}^{(-0.387 \text { days })}\left(R^{2}=0.72\right)$, was fitted using data from all replicates and both species to describe the change in $\Theta$ with time. (B) Relationship between daily decrease in substrate water content $(\Theta$ change $)$ and $\Theta$ in salvia (open circles) and vinca (closed circles). Error bars represent SEM $(n=5-6)$. The interactive effect of species $\times \Theta$ on $\Theta_{\text {change }}$ was significant. Linear equations $\Theta_{\text {change }}=$ $-0.03+0.57 \cdot \Theta\left(r^{2}=0.67 ; P<0.0001\right)$ and $\Theta_{\text {change }}=-0.01+0.24 \cdot \Theta\left(r^{2}=0.65\right.$; $P<0.0001)$ were fitted for salvia and vinca, respectively.

a few days after drought conditions. Plant water uptake rapidly decreased for salvia, but it decreased more gradually for vinca with drought progression (Fig. 1B). At $\Theta$ less than $0.10 \mathrm{~m}^{3} \cdot \mathrm{m}^{-3}$, the plant water uptake of salvia started to decrease to less than that of vinca, subsequently resulting in wilting. Vinca continued to extract water from the substrate at a $\Theta$ level less than that which resulted in wilting of salvia (Fig. 1B).

Wilting under drought conditions can be delayed in plants with smaller canopies compared to those with larger canopies. This is due to relatively lower rates of water extraction from the substrate due to smaller leaf area of plants with smaller canopies compared to those with larger canopies. Although wilting may be delayed, the $\Theta$ level at the time of wilting may not be different between the two groups unless differences in physiological responses to drought exist between them. In our study, vinca had a smaller canopy compared to salvia. However, the decrease in
$\Theta$ with drought progression was not different between species. Based on the fitted relationship between $\Theta_{\text {change }}$ and $\Theta$, plant water uptake of vinca continued at a $\Theta$ level below that of the wilting point of salvia (Fig. 1B) and resulted in significantly lower $\Theta$ at the time of wilting compared to that of salvia. This suggested that delayed wilting under drought conditions for vinca was likely due, in part, to differences in physiological acclimation between vinca and salvia.

$\mathbf{P N}_{A V G}, \mathbf{R D}_{-A V G}$, AND DCG. There were distinct temporal patterns in the net $\mathrm{CO}_{2}$ exchange rate during the drought for both species. When the lights were turned on following a dark cycle, $P_{n}$ increased to a peak value and then slightly decreased during the light period (Fig. 2) in both species. Beyond a species-dependent threshold $\Theta$ level, $\mathrm{P}_{\mathrm{n} \_ \text {avg }}$ declined steadily until the end of the study as the plants were exposed to increasingly severe drought stress. Similar responses were observed for $\mathrm{R}_{\mathrm{d} \_ \text {avg }}$ during the dark period; initially, the rates were higher (more negative) and gradually decreased (closer to zero) as drought stress severity increased (Fig. 2).

An analysis of data collected at the start of the experiment and the start of the wilting stages indicated that the interactive effect of species $\times$ time was not significant for $\mathrm{P}_{\mathrm{n} \_a v g}, \mathrm{R}_{\mathrm{d} \_a v g}$, and DCG. However, there were significant main effects of species and time on $\mathrm{P}_{\mathrm{n}_{\_} \text {avg }}$ and $\mathrm{DCG}$, whereas $\mathrm{R}_{\mathrm{d} \_ \text {avg }}$ was affected only by species (Table 1 ). Regardless of time, $\mathrm{P}_{\mathrm{n} \_ \text {avg }}$ and $\mathrm{R}_{\mathrm{d} \_ \text {avg }}$ were significantly higher, whereas $\mathrm{DCG}$ was numerically higher $(P=0.051)$ for salvia than for vinca (Table 1). These differences between species were partly due to differences in canopy size. Whole-plant gas exchange measurements at the start and wilting stages were not adjusted for differences in total leaf area because this requires destructive measurements. Therefore, the larger canopy of salvia likely resulted in the higher net $\mathrm{CO}_{2}$ exchange rate compared to that of vinca (Table 1). As expected, $\mathrm{P}_{\mathrm{n} \_ \text {avg }}$ and DCG were significantly lower during the start of the wilting stage compared to those at the start of the drought cycle for both species.

The response of normalized $\mathrm{P}_{\mathrm{n}_{-} \text {avg }}$ and DCG (i.e., percent maximum) to decreasing $\Theta$ was different between the two species based on $\Theta_{0}$ values (Table 2). For both $\mathrm{P}_{\mathrm{n}}$ avg and DCG, $\Theta_{0}$ values were significantly higher for salvia compared to vinca. A higher $\Theta_{0}$ value indicated that the threshold $\Theta$ at which $\mathrm{P}_{\mathrm{n} \_ \text {avg }}$ and DCG started to decline and eventually became zero was higher for salvia compared to vinca. In fact, $P_{n \_a v g}$ and DCG remained close to the maximum rate when $\Theta$ $>0.15 \mathrm{~m}^{3} \cdot \mathrm{m}^{-3}$, and they decreased sharply beyond the species-dependent threshold $\Theta$ (Fig. 3A, B, E, and F). The $\Theta$ at which $\mathrm{P}_{\mathrm{n}_{-} \text {avg }}$ and $\mathrm{DCG}$ decreased to $90 \%$ of the maximum were 0.10 and 0.13 to $0.15 \mathrm{~m}^{3} \cdot \mathrm{m}^{-3}$ for vinca and salvia, respectively (Fig. 3A, B, E, and F). No statistical differences in $b$ values (Table 2) indicated that the rates of decline of $\mathrm{P}_{\mathrm{n} \_ \text {avg }}$ and $\mathrm{DCG}$ with decreasing $\Theta$ were not different between the two species. In other words, the onset of drought stress was delayed for vinca; however, after the onset of stress, the rates of decline of $\mathrm{P}_{\mathrm{n}_{a} \text { avg }}$ and DCG were similar for the two species.

The sharp decrease in photosynthesis for both species below the threshold $\Theta$ was likely due to the difficulty maintaining $\Psi_{P}$ and $g_{\mathrm{S}}$ at severe levels of drought stress (Gindaba et al., 2005; McCree, 1986; Nemali and van Iersel, 2008; Xu and Zhou, 2005). Similar responses of leaf photosynthesis to $\Theta$ were reported for Vinca roseus (Kim and van Iersel, 2011), grasses [Leymus chinensis (Xu and Zhou, 2005)], field crops [Sorghum 


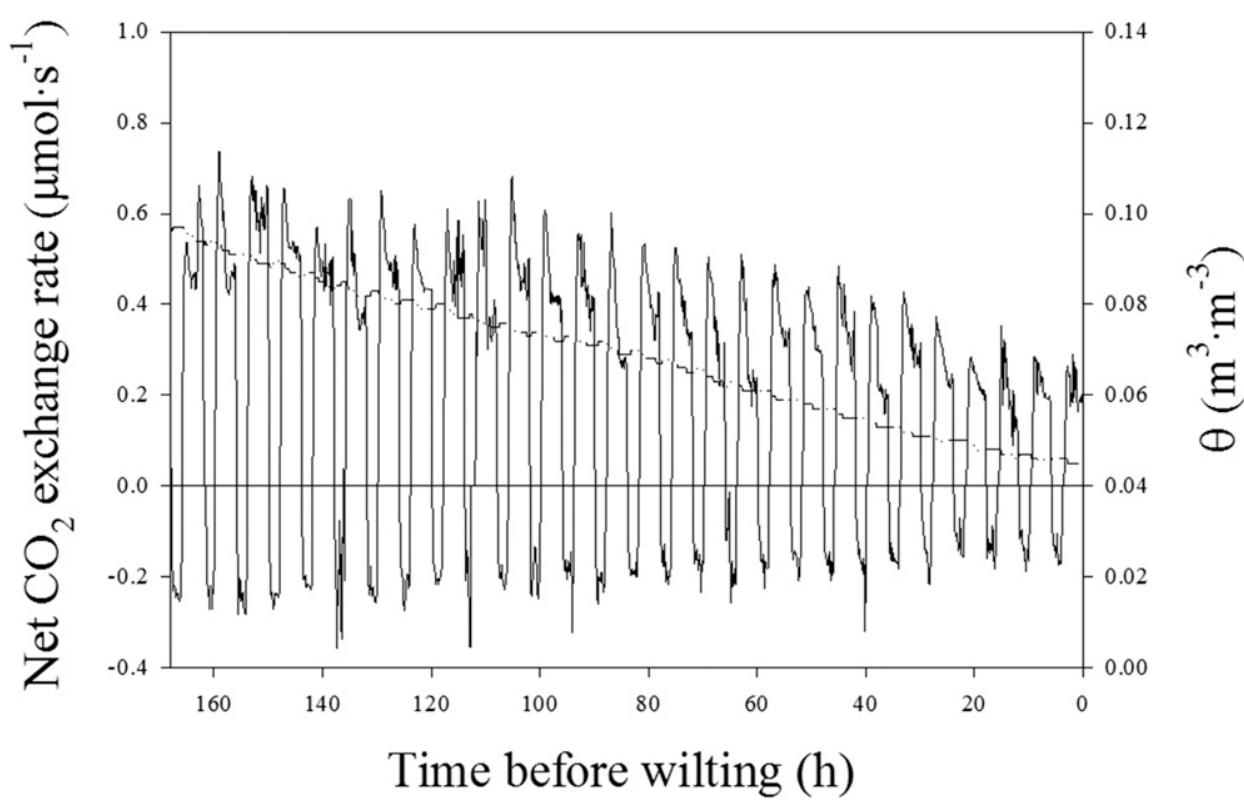

Fig. 2. Net $\mathrm{CO}_{2}$ exchange rates (solid line) and substrate water content $(\Theta)$ (dashed line) of vinca during the past $168 \mathrm{~h}(7 \mathrm{~d})$ of the drought cycle. Similar data were collected for salvia. Plants were exposed to cycles of $4 \mathrm{~h}$ of light (positive $\mathrm{CO}_{2}$ exchange rate or net photosynthesis rate) and $2 \mathrm{~h}$ of dark (negative $\mathrm{CO}_{2}$ exchange rate or dark respiration rate) periods. Note the gradual decrease in the net $\mathrm{CO}_{2}$ exchange rate with decreasing $\Theta$. bicolor (McCree, 1986)], and trees [Eucalyptus camaldulensis and E. globulus (Gindaba et al., 2005)]. Maintenance of positive net photosynthesis and carbon gain at lower $\Theta$ for vinca could be related to the continuation of plant water uptake at lower $\Theta$ levels under drought conditions for vinca compared to salvia (Fig. 1B).

The response of $\mathrm{R}_{\mathrm{d} \_a v g}$ to decreasing $\Theta$ was similar between the two species (Table 2). Generally the response of respiration to drought is highly variable among species. A decrease in respiration can occur as a consequence of a decrease in photosynthesis (HauptHerting at al., 2001) or irrespective of changes in photosynthesis under drought conditions (Flexas et al., 2005). Because there were no statistical differences in $\mathrm{R}_{\mathrm{d} \_a v g}$, differences in DCG were likely associated with observed differences in $\mathrm{P}_{\mathrm{n} \_a v g}$ with decreasing $\Theta$ between the species.
Table 1. Daily average whole-plant net photosynthesis $\left(\mathrm{P}_{\mathrm{n} \_a v g}\right)$, wholeplant respiration $\left(\mathrm{R}_{\mathrm{d} \_a v g}\right)$, and daily carbon gain (DCG) at the start of the experiment and when plants started to show wilting signs in salvia and vinca grown at $21^{\circ} \mathrm{C}(\mathrm{n}=5-6) .^{\mathrm{z}}$

\begin{tabular}{lcccc}
\hline \multirow{2}{*}{ Species } & Time & $\mathrm{P}_{\mathrm{n} \_a v g}$ & $\mathrm{R}_{\mathrm{d} \_a v g}$ & DCG \\
\cline { 5 - 5 } Salvia & Start & 0.58 & -0.28 & 27.1 \\
& Wilt & 0.31 & -0.21 & 11.8 \\
Vinca & Start & 0.44 & -0.15 & 20.9 \\
& Wilt & 0.18 & -0.11 & 7.4 \\
& & $P$ & & \\
Species & & 0.012 & 0.021 & 0.051 \\
Time & & $<0.0001$ & 0.489 & $<0.0001$ \\
Species $\times$ Time & & 0.903 & 0.558 & 0.760
\end{tabular}

${ }^{\mathrm{z}}$ Statistical analysis of main and interaction effects (analysis of variance) is shown at the bottom of the table.

Table 2. Estimated nonlinear regression parameters $\left(\Theta_{0}\right.$ and $\left.b\right)$ for the relationship between normalized (percent maximum) rates of whole-plant photosynthesis $\left(\mathrm{P}_{\mathrm{n} \_a v g}\right)$, whole-plant respiration $\left(\mathrm{R}_{\mathrm{d} \_ \text {avg }}\right)$, daily carbon gain $(\mathrm{DCG})$, and substrate water content $(\Theta)$ in salvia and vinca during the second drought cycle. ${ }^{\mathrm{z}}$

\begin{tabular}{lcccc}
\hline Measurement & Parameter & Salvia & Vinca & $P$ \\
\hline $\mathrm{P}_{\mathrm{n} \_a v g}$ & $\Theta_{0}$ & 0.071 & 0.051 & 0.031 \\
& $\mathrm{~b}$ & 0.024 & 0.018 & 0.505 \\
$\mathrm{R}_{\mathrm{d} \_a v g}$ & $\Theta_{0}$ & 0.024 & -0.06 & 0.459 \\
& $\mathrm{~b}$ & 0.043 & 0.084 & 0.387 \\
$\mathrm{DCG}$ & $\Theta_{0}$ & 0.078 & 0.054 & 0.013 \\
& $\mathrm{~b}$ & 0.037 & 0.018 & 0.181
\end{tabular}

${ }^{\bar{z}}$ Statistical differences between species are indicated using probability values $(n=5-6)$.

\section{Leaf scale responses to drought stress}

LEAF $\Psi_{\mathbf{L}}, \Psi_{\mathbf{S}}$, AND $\Psi_{\mathbf{P}}$. The interactive effect of species $\times$ time was not significant for $\Psi_{\mathrm{L}}, \Psi_{\mathrm{S}}$, and $\Psi_{\mathrm{P}}$ measurements performed at the start of the experiment and the start of the wilting stages. There was a significant main effect of time on $\Psi_{\mathrm{L}}, \Psi_{\mathrm{S}}$, and $\Psi_{\mathrm{P}}$ measurements. Due to drought stress, $\Psi_{\mathrm{L}}, \Psi_{\mathrm{S}}$, and $\Psi_{\mathrm{P}}$ were lower at the start of wilting compared to those at the start of the drought cycle (Table 3 ). When averaged across both measurement times, a more negative $\Psi_{\mathrm{S}}(P=0.063)$ and significantly higher $\Psi_{\mathrm{P}}$ were observed for vinca compared to salvia (Table 3 ). $\Psi_{\mathrm{L}}$ was not significantly different between species; however, it was more negative for vinca than for salvia at the wilting stage (Table 3). Collectively, more negative $\Psi_{\mathrm{S}}$ and significantly higher $\Psi_{\mathrm{P}}$ for vinca suggested increased levels of osmotic adjustment in vinca compared to salvia.

Stomatal Conductance. The interactive effect of species $\times$ time was not significant for $g_{\mathrm{S}}$. There was a significant main effect of time on $g_{S}$ because it was lower at the start of wilting compared to the start of the drought cycle for both species (Table 3). Lower $g_{\mathrm{S}}$ can limit photosynthesis under drought conditions (Boyle et al., 2016; Jones, 1985; Nemali and van Iersel, 2008) because it regulates the $\mathrm{CO}_{2}$ exchange between the atmosphere and leaf internal sites. This may be partly responsible for lower $\mathrm{P}_{\mathrm{n} \text { avg }}$ at wilting in both species (Table 1). Despite no statistical differences in $g_{S}$, between the species (Table 2), vinca maintained a higher $g_{S}$ (statistically not significant) at the start of the drought cycle (Table 3). Although $g_{\mathrm{S}}$ was not measured during the drought phase in our study, the possibility that $g_{S}$ could be higher in vinca than in salvia during the drought may not be ruled out because there was significantly higher $\Psi_{\mathrm{P}}$ and continuation of water uptake at lower $\Theta$ in vinca compared to salvia under drought conditions. 


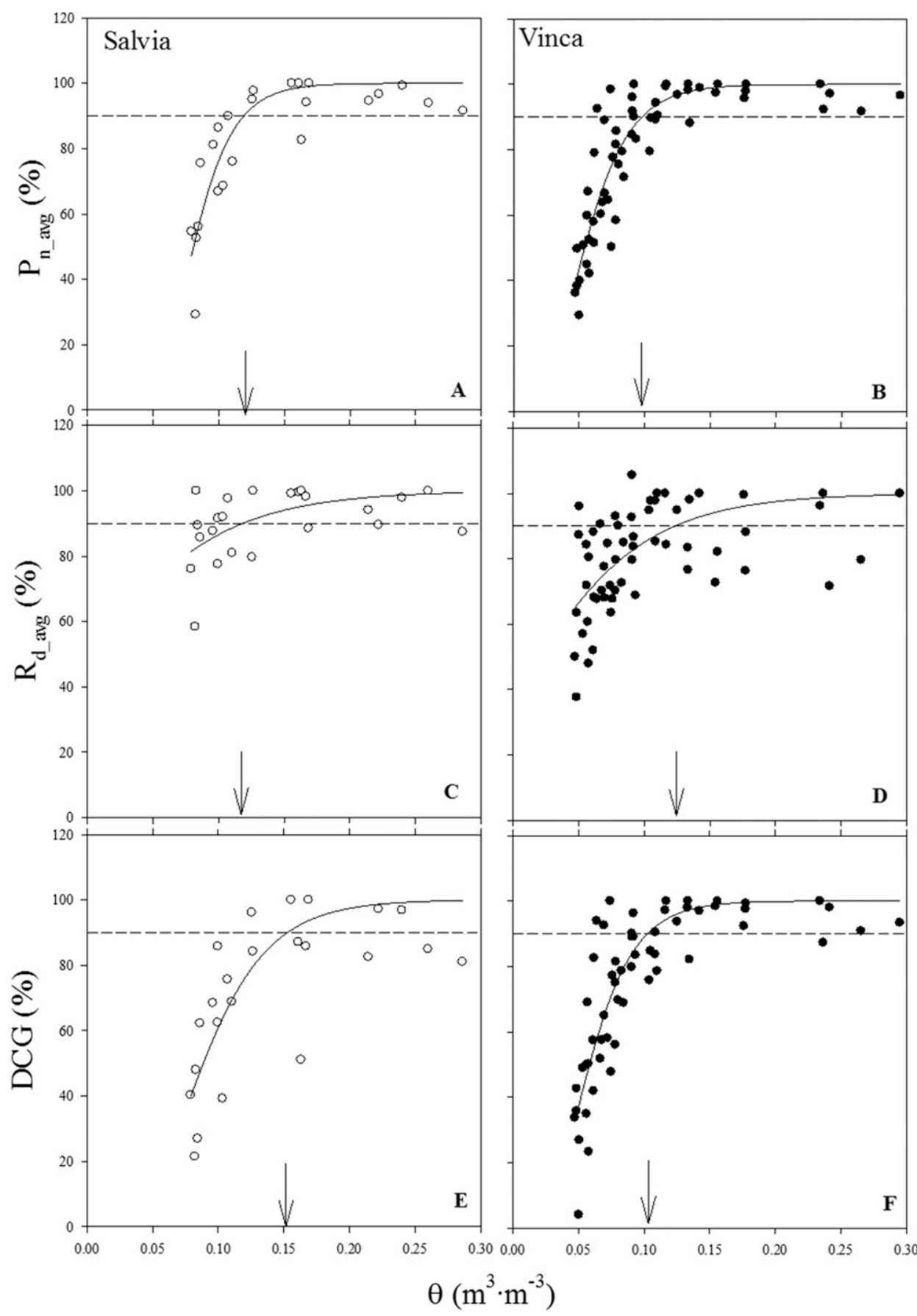

Fig. 3. Relationship between normalized (percent maximum) whole-plant photosynthesis $\left(\mathrm{P}_{\mathrm{n} \_a v g}\right)(\mathbf{A}$ and $\left.\mathbf{B})\right]$, wholeplant respiration $\left(\mathrm{R}_{\mathrm{d} \_ \text {avg }}\right)(\mathbf{C}$ and $\mathbf{D})$, and daily carbon gain $(\mathrm{DCG})(\mathbf{E}$ and $\left.\mathbf{F})\right]$ compared to the substrate water content $(\Theta)$ in salvia and vinca during the second drought cycle. Data were normalized to account for differences in canopy size between replications and species. Each data point represents a daily average value. Data from all replications $(n=5-6)$ are shown. The Gompertz function was fitted to the data: $f=100 \cdot \exp ^{-\exp }\left[-\frac{\left(-\theta_{0}\right)}{b}\right]$. Arrows indicate the substrate water content at which measured responses decreased to $90 \%$ of the maximum observed value.

$(\approx-0.70$ to $-0.75 \mathrm{MPa})$ between salvia and vinca. However, $\Psi_{S}$ of fully turgid vinca leaves after thorough rehydration following the second drought cycle was lower than the initial $\Psi_{\mathrm{S}}$. This resulted in a lower $\Psi_{\mathrm{S}}$ of rehydrated leaves of vinca compared to salvia (Fig. 4). There was a 0.37-MPa decrease in $\Psi_{S}$ of fully turgid leaves of vinca after exposure to drought $(-0.71$ to $-1.08 \mathrm{MPa}$ ) (Fig. 4). These results indicated the occurrence of $\mathrm{OA}$ in vinca, but not in salvia, under drought conditions. The OA refers to the accumulation of "compatible" organic and mineral solutes (e.g., glycine betaine, proline) in the vacuole and cytoplasm of the cell to maintain positive $\Psi_{\mathrm{P}}$ under drought conditions (Hsiao and $\mathrm{Xu}$, 2000; Sanders and Arndt, 2012; Serraj and Sinclair, 2002). The occurrence of $\mathrm{OA}$ during drought was documented in drought-resisting ornamental species like Rudbeckia (Chapman and Augé, 1994). Higher average $\Psi_{\mathrm{P}}$ in vinca than in salvia under drought conditions (Table 1) in our study was likely due to increased OA in vinca compared to that in salvia (Fig. 4). Increased OA may have also helped with the water uptake at lower $\Theta$ in vinca compared to salvia (Fig. 1B). Additionally, higher $\Psi_{\mathrm{P}}$ in vinca likely helped to continue photosynthesis and daily carbon gain in vinca than in salvia under drought conditions.

DARK-ADAPTED $\Phi_{\text {PSII }}$. A significantly higher dark-adapted $\Phi_{\text {PSII }}$ of fully rehydrated leaves following the second drought cycle was observed in vinca compared to salvia $(0.83 \pm 0.012$ vs. $0.79 \pm 0.011 ; P=$ $0.045)$. The value measured in vinca after exposure to drought stress was close to the maximum value seen for healthy leaves in many species (Björkman and Demmig, 1987). Dark adapted quantum efficiency is also known as intrinsic or maximum quantum efficiency of photosystem II when all reaction centers

\section{Cellular scale responses to drought stress}

Osmotic POTENTIAL OF FUlLy hydRATED Plants. The assessment of fully turgid leaves before imposing drought stress and after thorough rehydration at the end of the second drought cycle indicated a significant species $\times$ time interaction for $\Psi_{S}$. The osmotic potential of fully turgid leaves before exposing plants to drought conditions was not different are open (after dark adaptation). This measurement provides information about underlying processes that could affect photochemistry (Maxwell and Johnson, 2000). Changes in optical properties (increased reflectance) under drought conditions can also affect dark-adapted $\Phi_{\text {PSII }}$ values (Murchie and Lawson, 2013). However, differences in dark-adapted $\Phi_{\text {PSII }}$ between salvia and vinca were not likely associated with 
Table 3. Average leaf water $\left(\Psi_{\mathrm{L}}\right)$, osmotic potential $\left(\Psi_{\mathrm{s}}\right)$, turgor potential $\left(\Psi_{\mathrm{P}}\right)$, and stomatal conductance $\left(g_{\mathrm{S}}\right)$ to water at the start of the experiment and when plants started to show wilting signs in salvia and vinca grown at $21{ }^{\circ} \mathrm{C}(\mathrm{n}=5-6){ }^{\mathrm{z}}$

\begin{tabular}{|c|c|c|c|c|c|}
\hline & & $\Psi_{\mathrm{L}}$ & $\Psi_{\mathrm{s}}$ & $\Psi_{\mathrm{P}}$ & $g_{\mathrm{S}}$ \\
\hline Species & Time & $\mathrm{MPa}$ & $\mathrm{MPa}$ & $\mathrm{MPa}$ & $\mathrm{mmol} \cdot \mathrm{m}^{-2} \cdot \mathrm{s}^{-}$ \\
\hline \multirow[t]{2}{*}{ Salvia } & Start & -0.57 & -0.76 & 0.19 & 124.8 \\
\hline & Wilt & -1.61 & -1.38 & -0.23 & 29.9 \\
\hline \multirow[t]{2}{*}{ Vinca } & Start & -0.55 & -1.01 & 0.45 & 214.1 \\
\hline & \multicolumn{5}{|c|}{$P^{-1.04}$} \\
\hline Species & & 0.979 & 0.063 & 0.005 & 0.332 \\
\hline Time & & $<0.0001$ & $<0.0001$ & $<0.0001$ & 0.001 \\
\hline Species $\times$ Time & & 0.896 & 0.699 & 0.373 & 0.176 \\
\hline
\end{tabular}

${ }^{\mathrm{z}}$ Statistical analysis of main and interaction effects (analysis of variance) is shown at the bottom of the table.

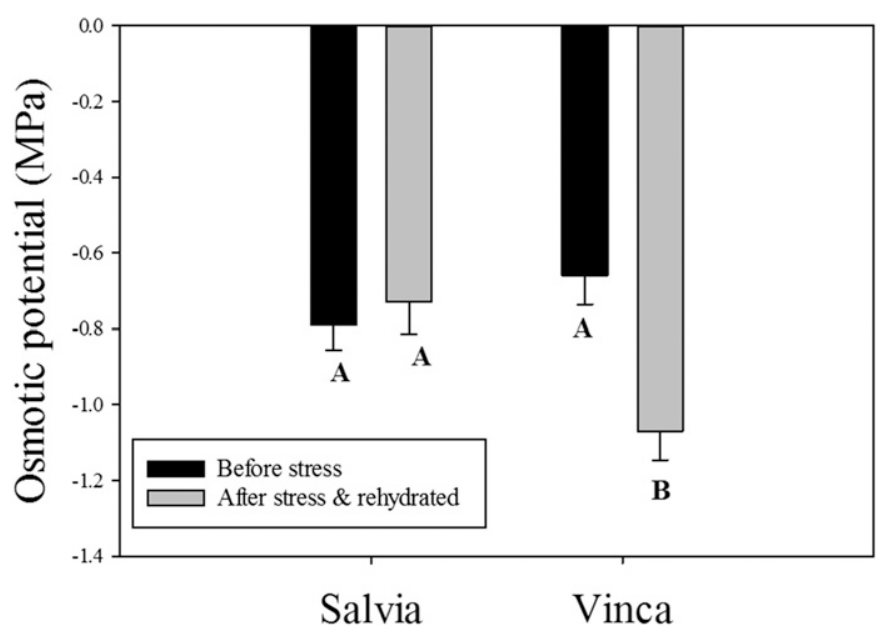

Fig. 4. Average $\Psi_{\mathrm{S}}$ of fully rehydrated leaves of salvia and vinca before exposing plants to drought and after exposure to two drought cycles. The osmotic potential of three to four leaves within each replication was measured $(n=6)$ at both times. Error bars indicate SEM. Means separated by a different letter indicate statistical significance at $P \leq 0.05$.

changes in the optical properties of leaves in the present study because measurements were obtained from fully rehydrated leaves after exposure to drought stress. Rapid decreases and gradual decreases in plant water uptake were observed in salvia and vinca, respectively, under drought conditions (Fig. 1B), suggesting that salvia experienced higher stress levels than vinca. Severe drought stress can damage photosystem II (Epron, 1997; Flexas et al., 1999) and reduce dark-adapted $\Phi_{\text {PSII. }}$ Lower dark $\Phi_{\text {PSII }}$ in salvia than in vinca after exposure to drought stress could be associated with damage to the reaction centers of photosystem II of salvia. This might have also resulted in lower quantum yield during the light period. Murchie and Niyogi (2011) indicated that lower dark-adapted $\Phi_{\text {PSII }}$ might have no effect on quantum yield during light and photosynthesis when plants are exposed to levels close to light saturation. However, the light level to which plants were exposed to in our study was $7.48 \mathrm{~mol} \cdot \mathrm{m}^{-2} \cdot \mathrm{d}^{-1}$, which is much lower than those that saturate whole plants of many species. Therefore, lower dark-adapted $\Phi_{\text {PSII }}$ could have potentially affected photosynthesis by lowering the quantum yield of the photosystem II during the light period in the current study.
In conclusion, the presence of OA in vinca and the absence of OA in salvia resulted in higher $\Psi_{\mathrm{P}}$ under drought conditions and continuation of water uptake at low $\Theta$ in vinca compared to salvia. These responses likely resulted in relatively lower levels of drought stress exposure in vinca compared to salvia and likely maintained higher dark-adapted $\Phi_{\text {PSII }}$ in vinca than in salvia. Collectively, these cellular and leaf scale responses likely resulted in the maintenance of whole-plant $\mathrm{P}_{\mathrm{n} \_a v g}$ and DCG under lower levels of $\theta$ in vinca compared to salvia. Based on our results, screening for traits like increased OA and higher dark-adapted $\Phi_{\text {PSII }}$ may be useful for developing new bedding plant cultivars that are tolerant to drought stress. Rapid measurements of chlorophyll fluorescence parameters (dark-adapted or light period $\Phi_{\text {PSII }}$ ) can be particularly useful for screening breeding populations because they are fast and simple. When comparing across different species, a relative value of these measurements should be used to account for intrinsic differences; for example, relative changes in these measurements compared to those of well-watered plants can be used for screening different species. Chlorophyll fluorescence measurements also may be useful for identifying the severity of drought stress experienced by plants, thereby aiding in crop management when the water availability is limited during bedding plant production.

\section{Literature Cited}

Boyle, R.K., M. McAinsh, and I.C. Dodd. 2016. Stomatal closure of Pelargonium $\times$ hortorum in response to soil water deficit is associated with decreased leaf water potential only under rapid soil drying. Physiol. Plant. 156:84-96.

Björkman, O. and B. Demmig. 1987. Photon yield of $\mathrm{O}_{2}$ evolution and chlorophyll fluorescence at $77 \mathrm{k}$ among vascular plants of diverse origins. Planta 170:489-504.

Castiglioni, P., D. Warner, R.J. Bensen, D.C. Anstrom, J. Harrison, M. Stoecker, M. Abad, G. Kumar, S. Salvador, R. D’Ordine, S. Navarro, S. Back, M. Fernandes, J. Targolli, S. Dasgupta, C. Bonin, M.H. Luethy, and J.E. Heard. 2008. Bacterial RNA chaperones confer abiotic stress tolerance in plants and improved grain yield in maize under water-limited conditions. Plant Physiol. 147:446-455.

Chapman, D.S. and R.M. Augé. 1994. Physiological mechanisms of drought resistance in four native ornamental perennials. J. Amer. Soc. Hort. Sci. 119:299-306.

Chaves, M.M., J.P. Maroco, and J.S. Pereira. 2003. Understanding plant responses to drought - From genes to the whole plant. Funct. Plant Biol. 30:239-264.

Comstock, J. and M. Mencuccini. 1998. Control of stomatal conductance by leaf water potential in Hymenoclea salsola (T. \& G.), a desert subshrub. Plant Cell Environ. 21:1029-1038.

da Silva, F.F., R. Wallach, and Y. Chen. 1993. Hydraulic properties of sphagnum peat moss and tuff (scoria) and their potential effects on water availability. Plant Soil 154:119-126.

Epron, D. 1997. Effects of drought on photosynthesis and on the thermotolerance of photosystem II in seedlings of cedar (Cedrus atlantica and C. libani). J. Expt. Bot. 48:1835-1841.

Ennahli, S. and H.J. Earl. 2005. Physiological limitations to photosynthetic carbon assimilation in cotton under water stress. Crop Sci. 45:2374-2382.

Flexas, J., J.M. Escalona, and H. Medrano. 1999. Water stress induces different levels of photosynthesis and electron transport rate regulation in grapevines. Plant Cell Environ. 22:39-48.

Flexas, J., J. Galmes, M. Ribas-Carbo, and H. Medrano. 2005. The effects of water stress on plant respiration, p. 85-94. In: H. Lambers and M. Ribas-Carbo (eds.). Plant respiration. Springer, Heidelberg, The Netherlands. 
Gindaba, J., A. Rozanov, and L. Negash. 2005. Photosynthetic gas exchange, growth and biomass allocation of two Eucalyptus and three indigenous tree species of Ethiopia under moisture deficit. For. Ecol. Mgt. 205:127-138.

Haupt-Herting, S., K. Klug, and H.P. Fock. 2001. A new approach to measure gross $\mathrm{CO}_{2}$ fluxes in leaves. Gross $\mathrm{CO}_{2}$ assimilation, photorespiration, and mitochondrial respiration in the light in tomato under drought stress. Plant Physiol. 126:388-396.

Hsiao, T.C. and L.K. Xu. 2000. Sensitivity of growth of roots versus leaves to water stress: Biophysical analysis and relation to water transport. J. Expt. Bot. 51:1595-1616.

Jaramillo, R.E., E.A. Nord, J.G. Chimungu, K.M. Brown, and J.P. Lynch. 2013. Root cortical burden influences drought tolerance in maize. Ann. Bot. 112:429-437.

Jones, H.J. 1985. Partitioning stomatal and non-stomatal limitations to photosynthesis. Plant Cell Environ. 8:95-104.

Kim, J. and M.W. van Iersel. 2011. Slowly developing drought stress increases photosynthetic acclimation of Catharanthus roseus. Physiol. Plant. 143:166-177.

Lynch, J.P. 2007a. Rhizoeconomics: The roots of shoot growth limitations. HortScience 42:1107-1109.

Lynch, J.P. 2007b. Roots of the second green revolution. Austral. J. Bot. 55:493-512.

McCree, K.J. 1986. Whole plant carbon balance during osmotic adjustment to drought and salinity stress. Austral. J. Plant Physiol. 13:33-43.

Maxwell, K. and G.N. Johnson. 2000. Chlorophyll fluorescence-a practical guide. J. Expt. Bot. 51:659-668.

Murchie, E.H. and K.K. Niyogi. 2011. Manipulation of photoprotection to improve plant photosynthesis. Plant Physiol. 155:86-92.

Murchie, E.H. and T. Lawson. 2013. Chlorophyll fluorescence analysis: A guide to good practice and understanding some new applications. J. Expt. Bot. 64:3983-3998.

National Aeronautics and Space Administration. 2014. U.S. National Drought Monitor. 6 May 2014. <http://earthobservatory.nasa.gov/ IOTD/view.php?id=83650>.

National Oceanic and Atmospheric Administration. 2016. Precipitation index. 14 Mar. 2019. <www7.ncdc.noaa.gov/CDO/ CDODivisionalSelect.jsp $>$.

Nemali, K.S. and M.W. van Iersel. 2006. An automated system for controlling drought stress and irrigation in potted plants. Sci. Hort. 110:292-297.
Nemali, K.S. and M.W. van Iersel. 2008. Physiological responses to different substrate water contents: Screening for high wateruse efficiency in bedding plants. J. Amer. Soc. Hort. Sci. 133:333340.

Nemali, K.S., C. Bonin, F.G. Dohleman, M. Stephens, W.R. Reeves, D.E. Nelson, P. Castiglioni, J.E. Whitsel, B. Sammons, R.A. Silady, D. Anstrom, R.E. Sharp, O.R. Patharkar, D. Clay, M. Coffin, M.A. Nemeth, M.E. Leibman, M. Luethy, and M. Lawson. 2015. Physiological responses related to increased grain yield under drought in the first biotechnology-derived drought tolerant maize. Plant Cell Environ. 38:1866-1880.

Nemali, K.S. and M. Stephens. 2014. Plant abiotic stress: Water, p. 335-342. In: N.K. Van Alfen (ed.). Encyclopedia of agriculture and food systems. Elsevier, London, UK.

Niu, G. and D.S. Rodriguez. 2006. Impact of drought and temperature on growth and leaf gas exchange of six bedding plant species under greenhouse conditions. HortScience 41:1408-1411.

Sanders, G. and S.K. Arndt. 2012. Osmotic adjustment under drought conditions, p. 199-229. In: R.A. Alvarez (ed.). Plant responses to drought stress: From morphological to molecular features. Springer, Heidelberg, The Netherlands.

Serraj, R. and T.R. Sinclair. 2002. Osmolyte accumulation: Can it really help increase crop yield under drought conditions? Plant Cell Environ. 25:333-341.

Tardieu, F. and W.J. Davies. 1992. Stomatal response to abscisic acid is a function of current plant water status. Plant Physiol. 98:540-545.

Tardieu, F., B. Parent, F. Caldiera, and C. Welcker. 2014. Genetic and physiological controls of growth under water deficit. Plant Physiol. 164:1628-1635.

Tezara, W., V.J. Mitchell, S.D. Driscoll, and D.W. Lawlor. 1999. Water stress inhibits plant photosynthesis by decreasing coupling factor and ATP. Nature 401:914-917.

U.S. Department of Agriculture. 2015. Floriculture crops 2015 summary. 26 Apr. 2016. <http://usda.mannlib.cornell.edu/usda/ current/FlorCrop/FlorCrop-04-26-2016.pdf>.

van Iersel, M.W. and B. Bugbee. 2000. A multiple chamber, semicontinuous, crop carbon dioxide exchange system: Design, calibration, and data interpretation. J. Amer. Soc. Hort. Sci. 125:86-92.

Xu, Z.-Z. and G.S. Zhou. 2005. Effects of water stress and high nocturnal temperature on photosynthesis and nitrogen levels of perennial grass Leymus chinensis. Plant Soil 269:131-139. 